\title{
Magnetic resonance imaging detects significant sex differences in human myocardial strain
}

\author{
Jennifer S Lawton*, Brian P Cupps, Andrew K Knutsen, Ningning Ma, Beckah D Brady, Lina M Reynolds and \\ Michael K Pasque
}

\author{
* Correspondence: \\ lawtonj@wudosis.wustl.edu \\ Department of Surgery, \\ Washington University School of \\ Medicine, 660 S. Euclid Ave., St. \\ Louis, Missouri, 63110, USA
}

\begin{abstract}
Background: The pathophysiology responsible for the significant outcome disparities between men and women with cardiac disease is largely unknown. Further investigation into basic cardiac physiological differences between the sexes is needed. This study utilized magnetic resonance imaging (MRI)-based multiparametric strain analysis to search for sex-based differences in regional myocardial contractile function.

Methods: End-systolic strain (circumferential, longitudinal, and radial) was interpolated from MRI-based radiofrequency tissue tagging grid point displacements in each of 60 normal adult volunteers (32 females).

Results: The average global left ventricular (LV) strain among normal female volunteers ( $n=32$ ) was significantly larger in absolute value (functionally better) than in normal male volunteers $(n=28)$ in both the circumferential direction (Male/ Female $=-0.19 \pm 0.02$ vs. $-0.21 \pm 0.02 ; p=0.025$ ) and Iongitudinal direction (Male/ Female $=-0.14 \pm 0.03$ vs. $-0.16 \pm 0.02 ; p=0.007)$

Conclusions: The finding of significantly larger circumferential and longitudinal LV strain among normal female volunteers suggests that baseline contractile differences between the sexes may contribute to the well-recognized divergence in cardiovascular disease outcomes. Further work is needed in order to determine the pathologic changes that occur in LV strain between women and men with the onset of cardiovascular disease.
\end{abstract}

\section{Background}

Cardiovascular disease is the number one cause of death in the United States. Each year, since 1984, more women than men have died from this disease [1]. Women are more likely to die following their first heart attack, are more likely to die following coronary artery bypass surgery, and are more likely to present with sudden death when compared to men [2-8]. The most promising avenue to understanding these clinical outcome disparities between men and women with cardiac disease is to investigate sex-related differences in basic physiological mechanisms such as those involved in the regional contractile function of the heart.

Recent investigations into sex-based differences in myocardial contractile function have utilized a broad spectrum of imaging methodologies and have demonstrated markedly conflicting results in this foundational area of basic cardiac physiology [9-17].

(C) 2011 Lawton et al; licensee BioMed Central Ltd. This is an Open Access article distributed under the terms of the Creative Commons Attribution License (http://creativecommons.org/licenses/by/2.0), which permits unrestricted use, distribution, and reproduction in any medium, provided the original work is properly cited. 
Cardiac MRI with radiofrequency tissue tagging has demonstrated the highest spatial and temporal resolution in the three-dimensional tracking of the intramyocardial point displacements that are utilized to generate 3D left ventricular strain maps [18-22].

\section{Methods}

\section{Patient Characteristics}

Sixty normal volunteers (age $33.1 \pm 10.8$ years) with no history of any cardiac disease underwent MRI-based multiparametric strain analysis. The study group consisted of 32 women and 28 men. No significant differences were found between the two groups in age (women: $34.8 \pm 10.4$ vs. men: $31.6 \pm 11.3$ years), systolic blood pressure (women: $117.0 \pm 10.4$ vs. men: $123.6 \pm 15.0 \mathrm{mmHg}$ ), or diastolic blood pressure (women: $73.7 \pm$ 7.9 vs. men: $73.6 \pm 11.4 \mathrm{mmHg}$ ). The Human Research Protection Office at Washington University, St. Louis, MO, approved the study and all subjects gave informed written consent.

\section{MR Imaging}

Imaging was performed in a 1.5 Tesla MR scanner (Siemens Medical Systems, Malvern, PA). Multiple short axis image sets were acquired in parallel planes at $8 \mathrm{~mm}$ intervals extending from the plane of the mitral valve to the apex of the heart. Additionally, four sets of long axis images oriented radially and intersecting the centroid of the ventricle were also obtained. For each selected imaging plane, a single-slice MR tagged image was collected with a sequence consisting of a spatial modulation of magnetization (SPAMM) radiofrequency tissue-tagging preparation [23,24] followed by a 2D balanced steady-state free precession (SSFP) cine image acquisition. Image acquisition was synchronized with real-time electrocardiogram (ECG) at the time of the MRI scanning. Typical imaging parameters were: tag spacing $8 \mathrm{~mm}$; slice thickness $8 \mathrm{~mm}$; repetition time $30.3 \mathrm{~ms}$, echo time $2.2 \mathrm{~ms}$, field of view $306 \times 350 \mathrm{~mm}$ and image matrix $168 \times 256$.

\section{Strain Calculations}

The method used to compute strain in this study has been described previously [20], so only a brief summary is provided here. Manually identified endocardial and epicardial boundaries from the tagged MR images were used to construct a finite element model of the LV. Utilizing the anterior and posterior junction points between the right ventricle (RV) free wall and intraventricular septum as anatomical markers, a mesh of twelve hexahedral elements (anterior, anterolateral, posterolateral, posterior, posteroseptal and anteroseptal myocardial walls) at the base and mid-LV regions, and six pentahedral elements at the apex, was constructed. Three-dimensional systolic displacements were computed from the deformation of the tag surfaces (Figure 1) using a previously described and validated method [20]. Analysis of the displacement data was carried out in the finite element analysis software package StressCheck (ESRD, Inc., St. Louis, Missouri). A continuous representation of displacement at any point within the domain of the model was obtained from a least squares fitting of the measured displacements. Values of circumferential, longitudinal and radial strain were computed for an evenly spaced grid in the element coordinate system $(15,300$ total 


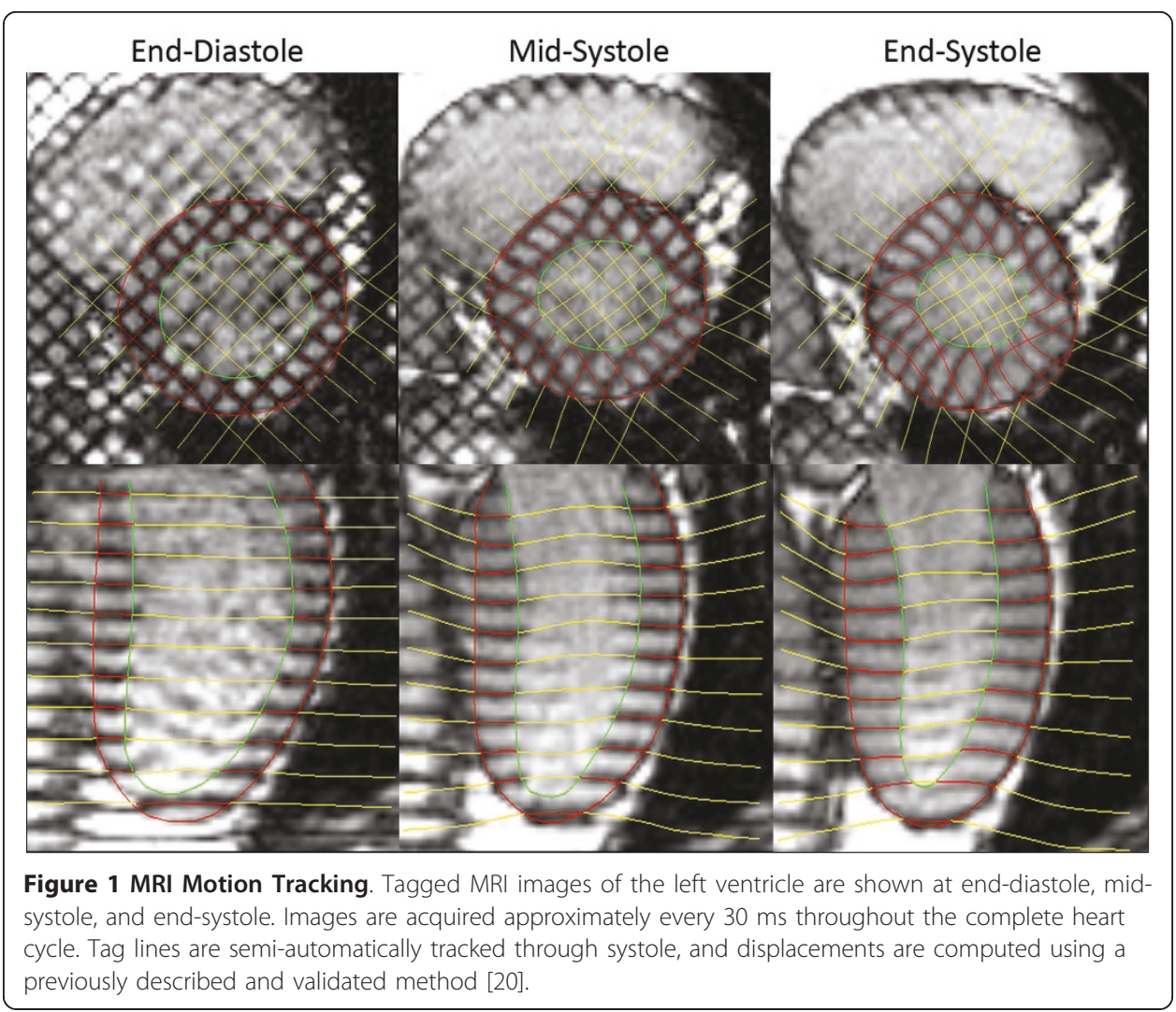

points). These point-wise measurements were used to compute regional average strain values for the anterior, anterolateral, posterolateral, posterior, posteroseptal and anteroseptal walls in each of the sixty volunteers. Additionally, average values in both men and women for each of the three strain components were computed at each of the 15,300 points covering the LV. The differences between these average strain values at corresponding points were used to generate color contour plots illustrating differences in contractile function throughout the LV in men and women.

\section{Statistical Analyses}

All strain values are expressed as mean \pm standard deviation. Regional and full model strain comparisons between men and women were done using an unpaired t-test. Pvalues were adjusted for multiple comparisons using the Dunn-Sidak correction. Normality of the strain data was tested using the Shapiro-Wilk statistic. In all cases, a pvalue of 0.05 was considered to be significant. Statistical analyses were carried out using the Systat software package (Systat Software, Inc., Chicago, IL).

In sample size determination, an effect size of .75 was estimated based on strain differences between male and females. A two-sided unpaired t-test sample size calculation with alpha $=.05$ produced a power of .81 if the two groups had 30 patients each. When all data was gathered, circumferential strain differences between males and females produced an effect size of one. Thus, in a post-hoc power calculation with 28 males and 32 females, the achieved power with alpha $=.05$ was .97. ( $G *$ Power 3.1.2). Age does not appear to be a significant variable in systolic strain levels [13] in the relatively narrow age range of our study group $(33.3 \pm 10.8$ years $)$. 


\section{Results}

A significant sex-based difference in two of three major components of regional myocardial strain was demonstrated, including a 10\% reduction (in absolute value) in global male circumferential strain compared to female: $\mathrm{M} / \mathrm{F}=-0.19 \pm 0.02$ vs. $-0.21 \pm 0.02$ $(\mathrm{p}=0.025)$. Similarly, global longitudinal strain comparison demonstrated a $13 \%$ male reduction versus female values: $\mathrm{M} / \mathrm{F}=-0.14 \pm 0.03$ vs. $-0.16 \pm 0.02(\mathrm{p}=0.007)$. Radial strain comparison demonstrated no significant difference between the sexes with the expected wide standard deviations: $\mathrm{M} / \mathrm{F}=0.12 \pm 0.05$ vs. $0.11 \pm 0.05(\mathrm{p}=0.789)$. Several significant differences in regional circumferential and longitudinal strain were seen between men and women (Figures 2 and 3, respectively), while no significant differences in regional radial strain were observed (Figure 4). Point-wise differences in average values of each strain component between men and women were used to create color contour plots to provide a visual illustration of baseline differences in contractile function between the sexes throughout the LV. These plots are presented in Figures 5, 6 and 7. Mean strain maps of each strain component are also demonstrated for both males and females (Figures 8, 9 and 10).

\section{Discussion}

Myocardial systolic strain is the foundational index in the quantification of regional myocardial contractile function. That there would be a significant sex-based difference in the contractile function of human myocardium at this most basic level is not intuitive. Nonetheless, this application of advanced mathematical analyses to the highly accurate spatial and temporal left ventricular geometrical data supplied by magnetic

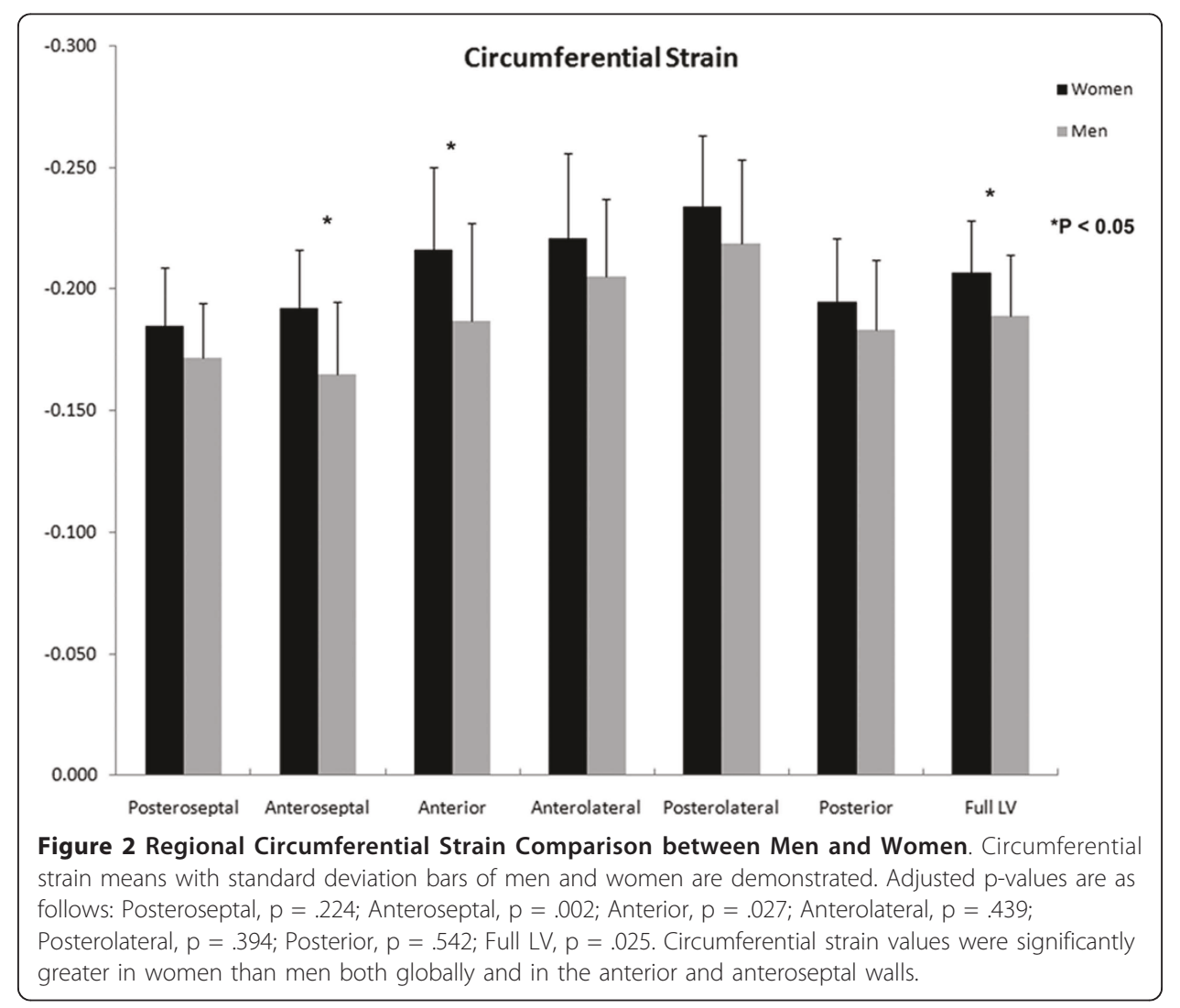



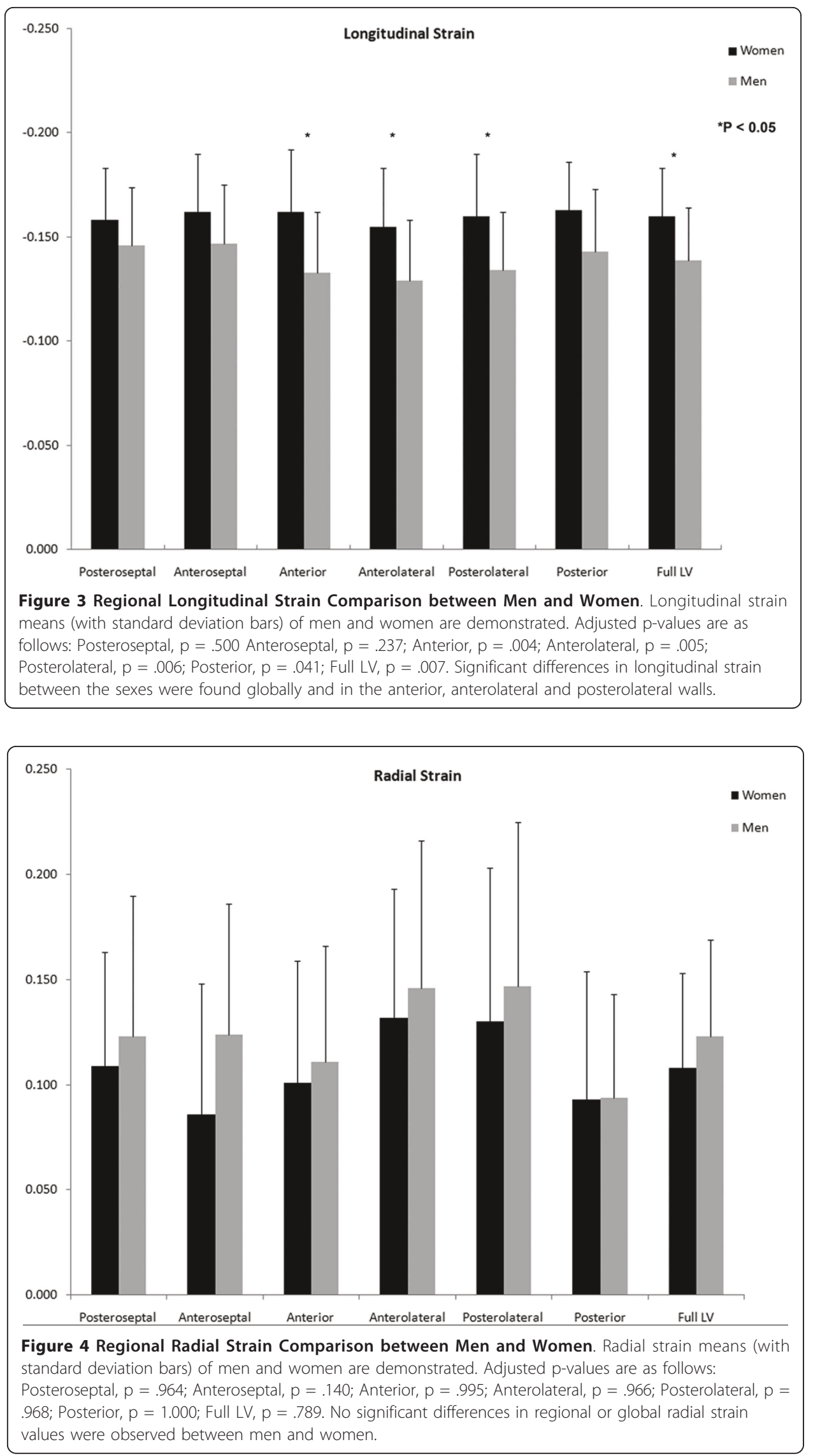


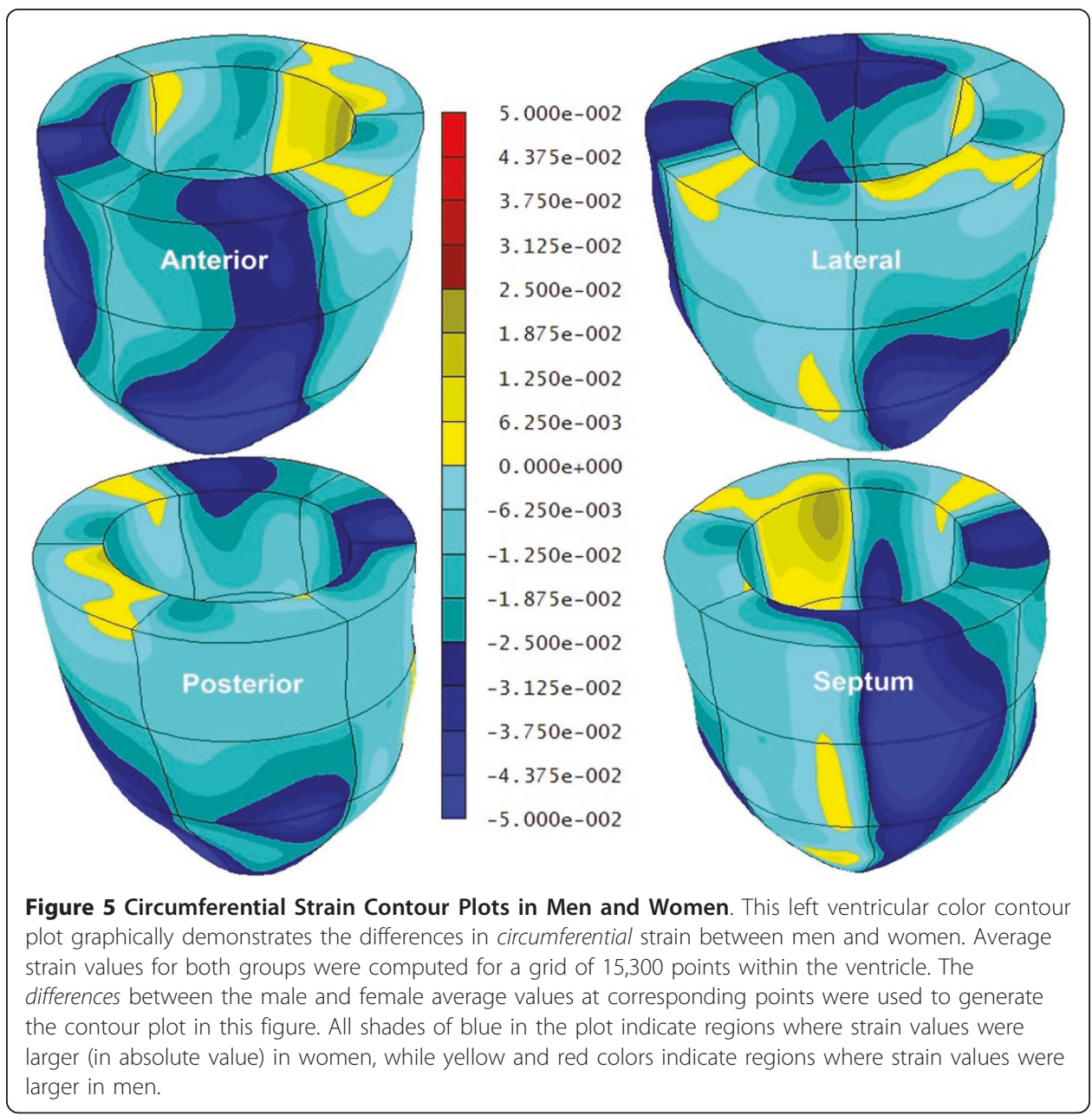

resonance tracking of radiofrequency tag planes in the in vivo human myocardium has characterized a foundational sex-based difference in myocardial mechanical function at its most basic level. The contractile information supplied by the application of these advanced engineering analyses in the clinical setting is the foundation upon which future diagnostic and therapeutic algorithms may well be based [25-27]. The establishment of a normal human strain database, as characterized in this study, is critical to any attempts to normalize strain data since all components of myocardial strain are geometrically heterogeneous and now, as a result of this investigation, must also be normalized based on sex. The clinical implications of the availability of a geometrical and sex differentiated normal human strain database are potentially profound. Such a database enables the accurate normalization of patient-specific systolic strain components thus uniquely allowing these strain indices (with often widely variable normal data ranges) to be combined into powerful composite multiparametric strain analyses to accurately characterize in vivo human left ventricular regional and transmural myocardial contractile function [28].

Previous studies on strain differences between the sexes have reported conflicting results. In 2009, Neizel found no significant difference in peak circumferential strains between the sexes utilizing SENC imaging [10]. Similar to our study, Hurlburt reported 


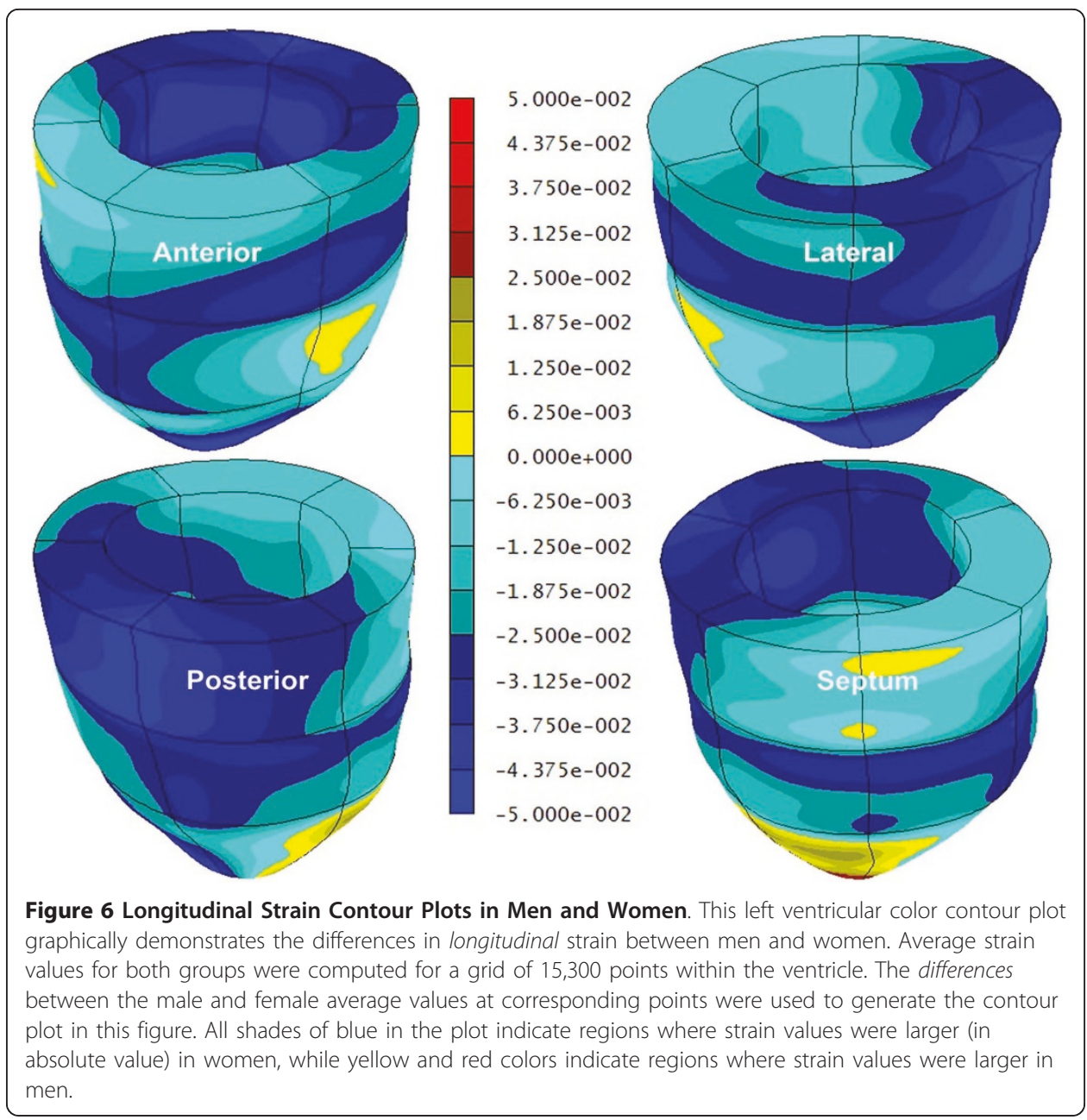

significant differences in both circumferential and longitudinal strain between men and women using speckle-tracking echocardiography [11]. In 2011, Reckefuss found longitudinal strain to be significantly higher in women but no difference between the sexes in radial strain [12]. Kuznetsova reported radial strain being significantly higher in women than in men, but longitudinal strain having no significant differences [17]. Sun found no sex-related strain differences [13]. Several studies have investigated the relationship between MRI measured strains and other parameters utilizing data collected as part the Multi-Ethnic Study of Atherosclerosis (MESA) [14-16]. In 2005, Rosen and colleagues found that the relationship between peak systolic circumferential strain and the ratio of LV mass to end-diastolic volume is significantly modified by gender [16]. In a subsequent manuscript, Rosen reported a significant relationship between CRP levels and regional LV function in men, but found no association in women [15]. Interestingly, in another study using data from MESA participants, Fernandes reported a direct significant relationship between ejection fraction and circumferential strain that did not differ by gender [14]. Previously, noninvasive assessment of cardiac function in women has suggested that they have higher baseline ejection fraction compared to men [9]. Clearly, there is significant discord in the reported results of clinical investigation into sex-based differences in myocardial strain. 


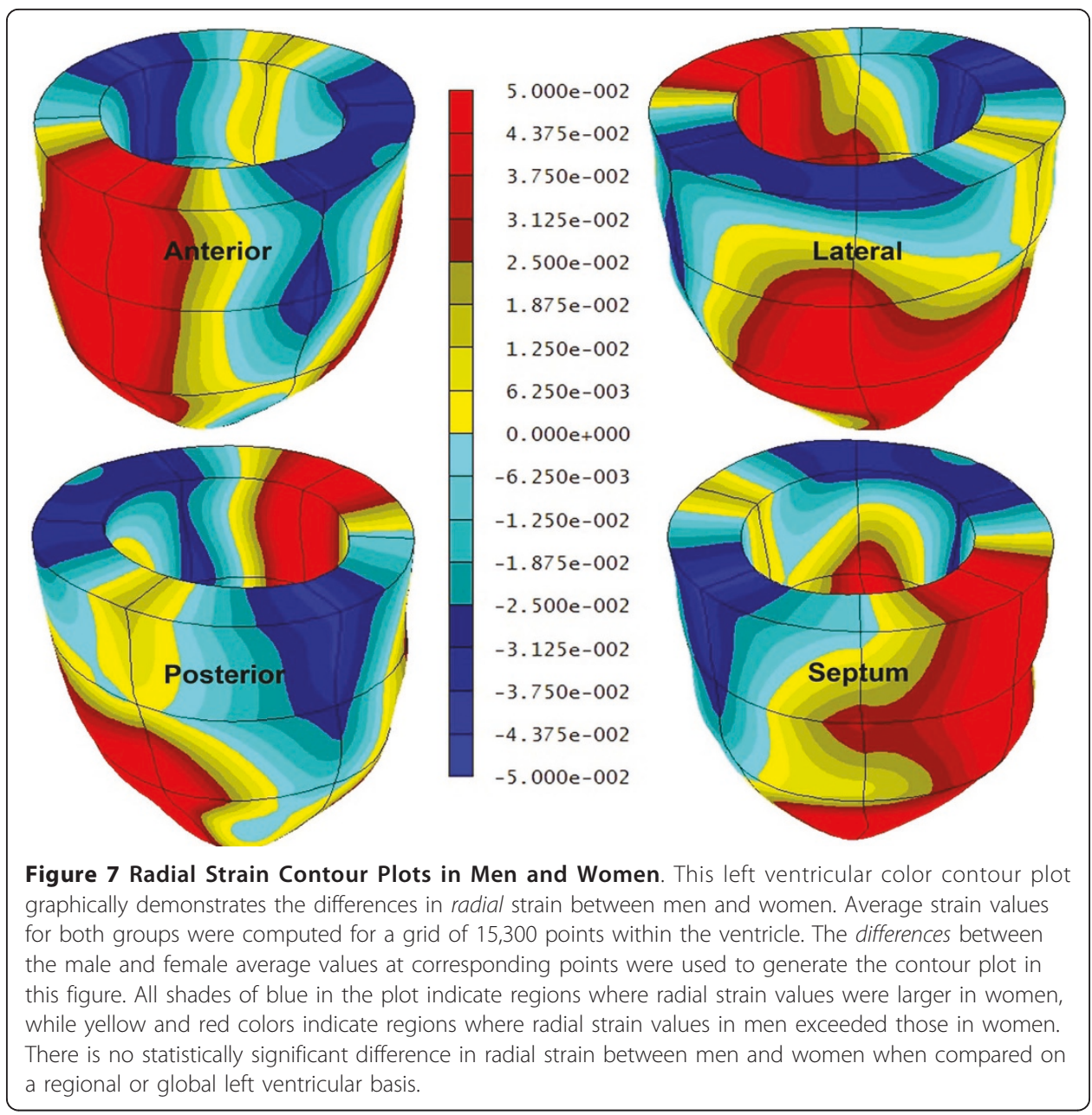

Significantly, all of these previous studies were two-dimensional in nature. That is, the regional strain values from these studies were based on measurements from a single imaging plane. In contrast, the method used in the present investigation combines data from multiple planes to generate three-dimensional displacements that more

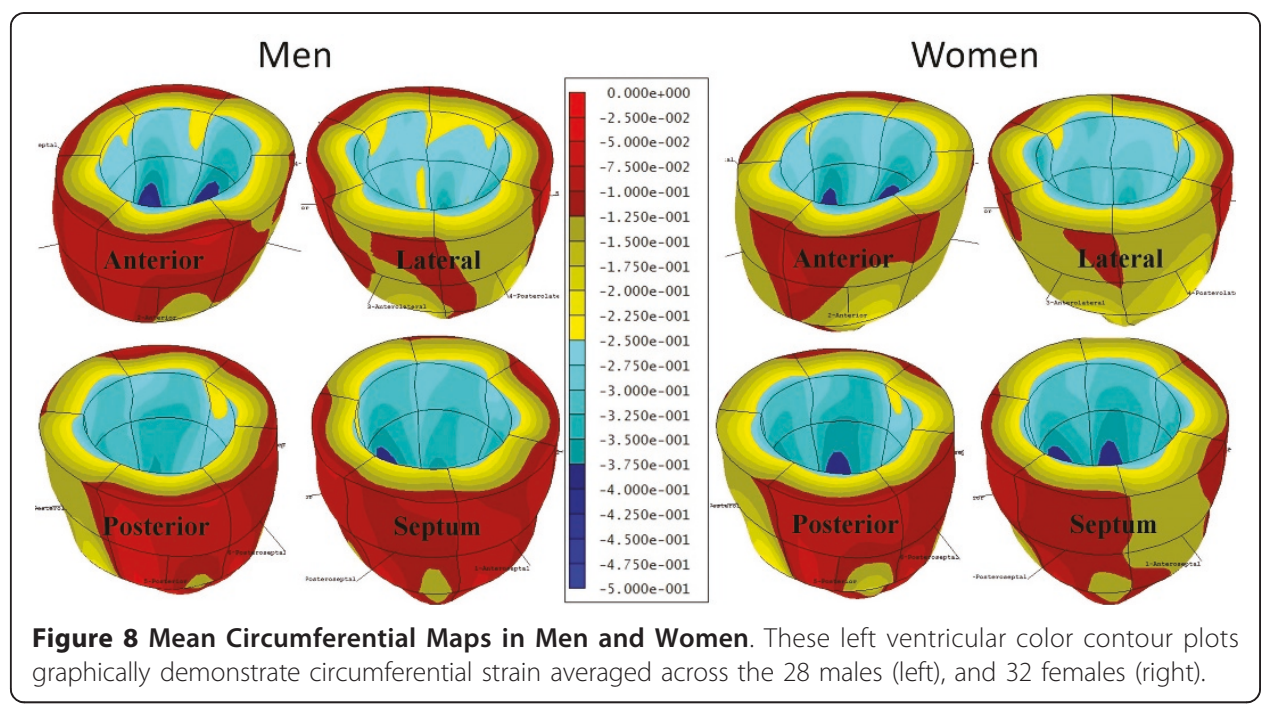




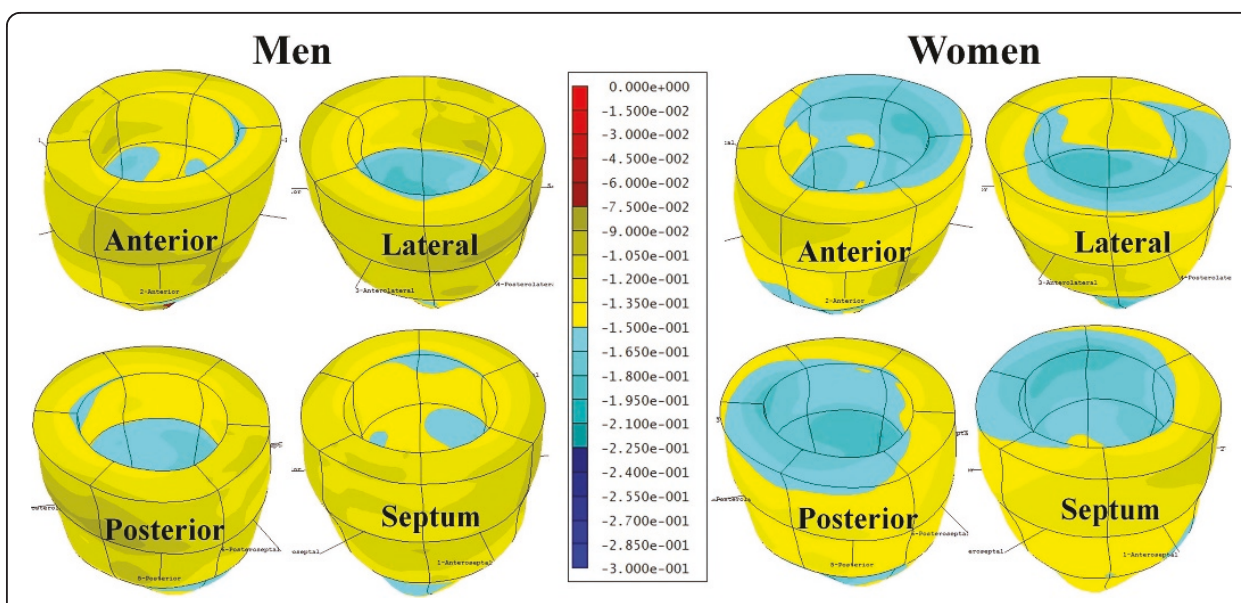

Figure 9 Mean Longitudinal Strain Maps in Men and Women. These left ventricular color contour plots graphically demonstrate longitudinal strain averaged across the 28 males (left), and 32 females (right).

accurately reflect the true myocardial contractile motion of the left ventricle. Of equal importance, the data from this study provides an atlas of strain values from men and women that is generated from the cardiac imaging modality with the highest spatial and temporal resolution. This database information is retained in a format that can be used to generate sex-based normalized measures of contractile function in different patient populations. This data provides a springboard from which investigators can fully characterize sex differences in contractile function and understand their role in heart disease.

Further strengths of our multi-parametric strain approach are found in the use of a $p$-version finite element model to estimate strain in the left ventricle. A least-squares fit of each component of the displacement vectors is computed over the elements of the mesh. The result is a continuous distribution of 3D strain estimates over the entire left ventricle. This is in contrast to a more common approach of computing derivatives on a grid of points using finite differences. We acknowledge that some limitations do exist in our approach. The calculated fits and strain estimates are only as good as the displacement vectors obtained from the imaging data. Image noise and patient

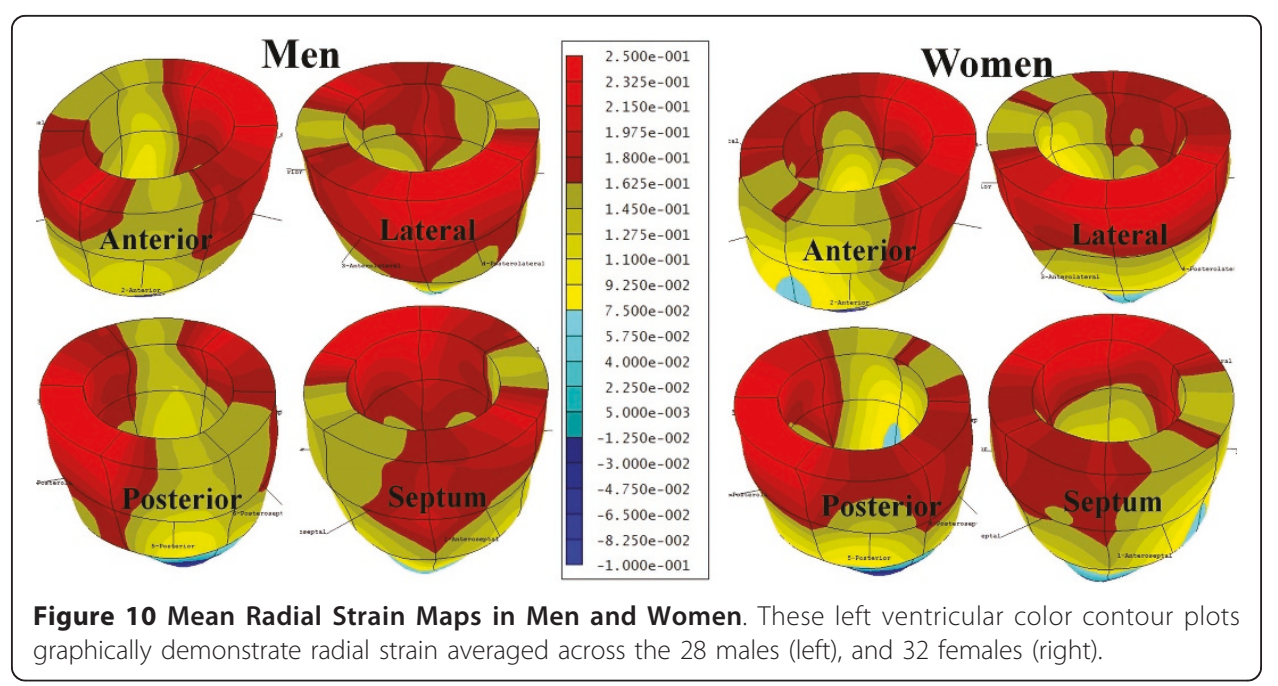


movement between breath holds can introduce error into the measured displacement vectors. The fact that the significant differences in strain were demonstrated in our investigation only in the primary directions of myocyte contraction (circumferential and longitudinal) is not surprising. Measurements of radial strain from tagged MR images tend to be more variable than similarly obtained measurements of circumferential or longitudinal strain [29]. It has been postulated that this variability is in part attributable to the reduced density of tag lines in the radial direction typically available on tagged MR images [30]. The variability of the calculated radial strain values likely contributes to the lack of observed significant differences in radial strain between the sexes seen in this study.

\section{Conclusions}

Our data suggest that at least prior to the development of cardiovascular disease, women have greater systolic strain than their male counterparts. The assumption that investigations into the regional contractile function of the heart can be referenced to the normal average and standard deviation of the general population is no longer appropriate. The sex-based differences in systolic myocardial strain that have been established by this investigation must be accounted for in future investigations of regional contractile function. Fundamental to any such clinical investigation is the availability of a normal human strain database (such as that utilized by our laboratory in this investigation) that allows the normalization of patient-specific strain to the appropriate sex-based normal average and standard deviation. The normal human left ventricular strain information from 60 normal volunteers that was utilized in this investigation is available upon request from our laboratory.

\footnotetext{
Acknowledgements and Funding

Supported by NIH Grants HL069967, HL064869 and NIH/NCRR Washington University-CTS Grant Number UL1 RR024992.
}

\section{Authors' contributions}

$J \mathrm{~L}$ conceived the study, participated in its design and data analysis and drafted the manuscript. MP directs the laboratory and participated directly in the data analysis, statistical approach, and manuscript design and crafting. BC participated in image acquisition, image analysis, data analysis and statistical approach. AK, NM and BB assisted in image analysis, data analysis and statistical approach. LR assisted in image data acquisition, regulatory management, and data analysis and management. Final approval of the final version of the manuscript was given by all authors.

\section{Competing interests}

Authors Michael K. Pasque and Brian P. Cupps have a financial interest related to the intellectual property of the computer software developed and used in this research study through the company CardioWise, LLC. Dr. Pasque, Dr. Cupps, and Washington University may receive income based on a license of related technology by the University to CardioWise, LLC. CardioWise, LLC did not support this work. All remaining authors, including Dr. Jennifer S. Lawton, Andrew K. Knutsen, Ningning Ma, Beckah D. Brady and Lina M. Reynolds have no competing interests.

Received: 18 April 2011 Accepted: 22 August 2011 Published: 22 August 2011

References

1. 2008 Heart and Stroke Statistical Update. [http://www.americanheart.org]

2. Chandra NC, Ziegelstein RC, Rogers WJ, Tiefenbrunn AJ, Gore JM, French WJ, Rubison M: Observations of the treatment of women in the United States with myocardial infarction: a report from the National Registry of Myocardial Infarction-I. Archives of internal medicine 1998, 158:981-988.

3. Daly C, Clemens F, Lopez Sendon JL, Tavazzi L, Boersma E, Danchin N, Delahaye F, Gitt A, Julian D, Mulcahy D, Ruzyllo W, Thygesen K, Verheugt F, Fox K: Gender differences in the management and clinical outcome of stable angina. Circulation 2006, 113:490-498.

4. Daugherty SL, Peterson PN, Magid DJ, Ho PM, Bondy J, Hokanson JE, Ross CA, Rumsfeld JS, Masoudi FA: The relationship between gender and clinical management after exercise stress testing. American heart journal 2008, 156:301-307 
5. Mosca L, Linfante AH, Benjamin EJ, Berra K, Hayes SN, Walsh BW, Fabunmi RP, Kwan J, Mills T, Simpson SL: National study of physician awareness and adherence to cardiovascular disease prevention guidelines. Circulation 2005, 111:499-510

6. Tsang TS, Barnes ME, Gersh BJ, Hayes SN: Risks of coronary heart disease in women: current understanding and evolving concepts. Mayo Clinic proceedings 2000, 75:1289-1303.

7. Vaccarino V, Abramson JL, Veledar E, Weintraub WS: Sex differences in hospital mortality after coronary artery bypass surgery: evidence for a higher mortality in younger women. Circulation 2002, 105:1176-1181.

8. Wenger NK, Shaw LJ, Vaccarino V: Coronary heart disease in women: update 2008. Clinical pharmacology and therapeutics 2008, 83:37-51.

9. Merz CN, Moriel M, Rozanski A, Klein J, Berman DS: Gender-related differences in exercise ventricular function among healthy subjects and patients. American heart journal 1996, 131:704-709.

10. Neizel M, Lossnitzer D, Korosoglou G, Schaufele T, Lewien A, Steen H, Katus HA, Osman NF, Giannitsis E: Strainencoded (SENC) magnetic resonance imaging to evaluate regional heterogeneity of myocardial strain in healthy volunteers: Comparison with conventional tagging. J Magn Reson Imaging 2009, 29:99-105.

11. Hurlburt HM, Aurigemma GP, Hill JC, Narayanan A, Gaasch WH, Vinch CS, Meyer TE, Tighe DA: Direct ultrasound measurement of longitudinal, circumferential, and radial strain using 2-dimensional strain imaging in normal adults. Echocardiography 2007, 24:723-731.

12. Reckefuss N, Butz T, Horstkotte $D$, Faber $L$ : Evaluation of longitudinal and radial left ventricular function by twodimensional speckle-tracking echocardiography in a large cohort of normal probands. The international journal of cardiovascular imaging 2011, 27:515-526.

13. Sun JP, Popovic ZB, Greenberg NL, XU XF, Asher CR, Stewart WJ, Thomas JD: Noninvasive quantification of regional myocardial function using Doppler-derived velocity, displacement, strain rate, and strain in healthy volunteers: effects of aging. J Am Soc Echocardiogr 2004, 17:132-138.

14. Fernandes VR, Edvardsen T, Rosen BD, Carvalho B, Campos O, Cordeiro MA, Kronmal R, Bluemke DA, Lima JA: The influence of left ventricular size and global function on regional myocardial contraction and relaxation in an adult population free of cardiovascular disease: a tagged CMR study of the MESA cohort. J Cardiovasc Magn Reson 2007, 9(6):921-930.

15. Rosen BD, Cushman M, Nasir K, Bluemke DA, Edvardsen T, Fernandes V, Lai S, Tracy RP, Lima JA: Relationship between C-reactive protein levels and regional left ventricular function in asymptomatic individuals: the Multi-Ethnic Study of Atherosclerosis. Journal of the American College of Cardiology 2007, 49:594-600.

16. Rosen BD, Edvardsen T, Lai S, Castillo E, Pan L, Jerosch-Herold M, Sinha S, Kronmal R, Arnett D, Crouse JR, Heckbert SR, Bluemke DA, Lima JA: Left ventricular concentric remodeling is associated with decreased global and regional systolic function: the Multi-Ethnic Study of Atherosclerosis. Circulation 2005, 112:984-991.

17. Kuznetsova T, Herbots L, Richart T, D'Hooge J, Thijs L, Fagard RH, Herregods MC, Staessen JA: Left ventricular strain and strain rate in a general population. Eur Heart J 2008, 29:2014-2023.

18. Denney TS, Prince JL: Reconstruction of 3D left ventricular motion from planar tagged cardiac MR images: an estimation theoretic approach. IEEE Trans Med Imaging 1995, 14(4):625-635.

19. Huang J, Abendschein D, Davila-Roman VG, Amini AA: Spatio-temporal tracking of myocardial deformations with a 4-D B-spline model from tagged MRI. IEEE Trans Med Imaging 1999, 18:957-972.

20. Moulton MJ, Creswell LL, Downing SW, Actis RL, Szabo BA, Vannier MW, Pasque MK: Spline surface interpolation for calculating 3-D ventricular strains from MRI tissue tagging. Am J Physiol 1996, 270:H281-297.

21. Young AA, Axel L: Three-dimensional motion and deformation of the heart wall: estimation with spatial modulation of magnetization-a model-based approach. Radiology 1992, 185:241-247.

22. Young AA, Kraitchman DL, Dougherty L, Axel L: Tracking and finite element analysis of stripe deformation in magnetic resonance imaging. IEEE Trans Med Imaging 1995, 14:413-421.

23. Axel L, Dougherty L: MR imaging of motion with spatial modulation of magnetization. Radiology 1989, 171:841-845.

24. Axel L, Dougherty L: Heart wall motion: improved method of spatial modulation of magnetization for MR imaging. Radiology 1989, 172:349-350.

25. Bree D, Wollmuth JR, Cupps BP, Krock MD, Howells A, Rogers J, Moazami N, Pasque MK: Low-dose dobutamine tissuetagged magnetic resonance imaging with 3-dimensional strain analysis allows assessment of myocardial viability in patients with ischemic cardiomyopathy. Circulation 2006, 114:133-36.

26. Moustakidis P, Cupps BP, Pomerantz BJ, Scheri RP, Maniar HS, Kates AM, Gropler RJ, Pasque MK, Sundt TM: Noninvasive, quantitative assessment of left ventricular function in ischemic cardiomyopathy. The Journal of surgical research 2004, 116:187-196.

27. Pomerantz BJ, Wollmuth JR, Krock MD, Cupps BP, Moustakidis P, Kouchoukos NT, Davila-Roman VG, Pasque MK: Myocardial systolic strain is decreased after aortic valve replacement in patients with aortic insufficiency. The Annals of thoracic surgery 2005, 80:2186-2192.

28. Cupps BP, Bree DR, Wollmuth JR, Howells AC, Voeller RK, Rogers JG, Pasque MK: Myocardial viability mapping by magnetic resonance-based multiparametric systolic strain analysis. The Annals of thoracic surgery 2008, 86:1546-1553.

29. Denney $T \mathrm{Jr}$, Gerber B, Yan L: Unsupervised reconstruction of a three-dimensional left ventricular strain from parallel tagged cardiac images. Magn Reson Med 2003, 49:743-754.

30. Guccione JM, Walker JC, Beitler JR, Moonly SM, Zhang P, Guttman MA, Ozturk C, McVeigh ER, Wallace AW, Saloner DA, Ratcliffe MB: The effect of anteroapical aneurysm plication on end-systolic three-dimensional strain in the sheep: a magnetic resonance imaging tagging study. The Journal of thoracic and cardiovascular surgery 2006, 131:579-586, e573.

doi:10.1186/1475-925X-10-76

Cite this article as: Lawton et al: Magnetic resonance imaging detects significant sex differences in human myocardial strain. BioMedical Engineering OnLine 2011 10:76. 